\section{Kounis syndrome: Is ceftriaxone or metronidazole responsible for acute myocardial infarction? \\ A rare case}

\author{
Abdulkadir Çakmak (D), Gökhan Keskin (D) \\ Department of Cardiology, Faculty of Medicine, Amasya University; \\ Amasya-Turkey
}

\section{Introduction}

Kounis syndrome (KS) was first described by Kounis as an allergic angina syndrome progressing to allergic myocardial infarction (1). Further research about KS revealed that it is a multiorgan and multidisciplinary condition (2). In this case report, we present a case of myocardial infarction caused by intravenous (IV) ceftriaxone and IV metronidazole administration.

\section{Case Report}

A 33-year-old male patient with a diagnosis of acute appendicitis was treated with IV ceftriaxone and IV metronidazole. Approximately 30 minutes later, the patient complained of severe chest pain, nausea, itching, and widespread rash. Antihistaminic therapy was administered to the patient, and electrocardiography (ECG) revealed an acute ST elevation.

The patient had no history of allergic anaphylaxis or any medication-related complications. His physical examination findings and blood pressure levels were normal. He had no fever but had extensive skin rash. His ECG revealed normal sinus rhythm, a 2-mm ST elevation in D1-aVL, and a 2-mm ST depression in D2-D3, v3-6 (Fig. 1). An acute high lateral myocardial infarction was suspected. Bedside echocardiography (ECHO) showed normal ejection fraction.

The patient was initially treated with subcutaneous adrenaline, IV dexamethasone $(8 \mathrm{mg})$, IV prednisolone $(120 \mathrm{mg})$, and IV pheniramine maleate $(45.5 \mathrm{mg})$ in $2 \mathrm{~mL}$ for the diagnosis of anaphylactic reaction. Coronary angiography revealed normal coronary arteries (Fig. 2). Control ECG of the patient showed that ST elevations and ST depression returned to the isoelectric line (Fig. 2). The patient was followed up in the coronary intensive care unit, and IV nitroglycerine treatment was started. Approximately 90 minutes after the initial onset of chest pain, the patient's chest pain completely disappeared. In serial ECG follow-up, ST abnormalities were completely normalized and declined to isoelectric line. Laboratory tests revealed normal hemoglobin and eosinophil levels. Neutrophil predominance was detected in the peripheral blood smear. Troponin I was elevated to 2.89 (normal range: $0-0.16$ ). The patient was discharged 72 hours later. ECG and ECHO findings before discharge were completely normal.

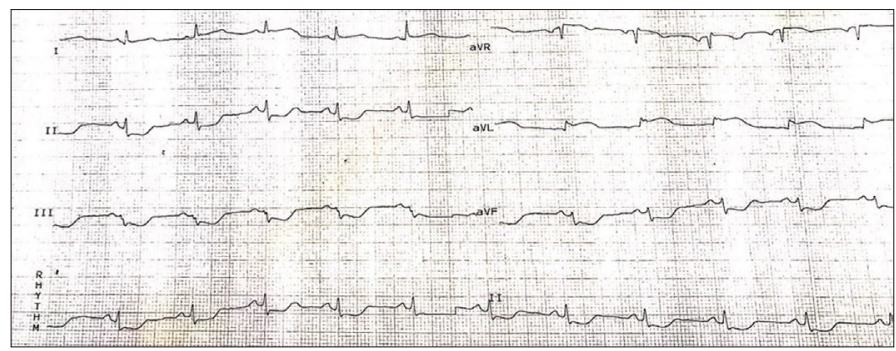

Figure 1. Primary ECG record of the patient at the cardiology department

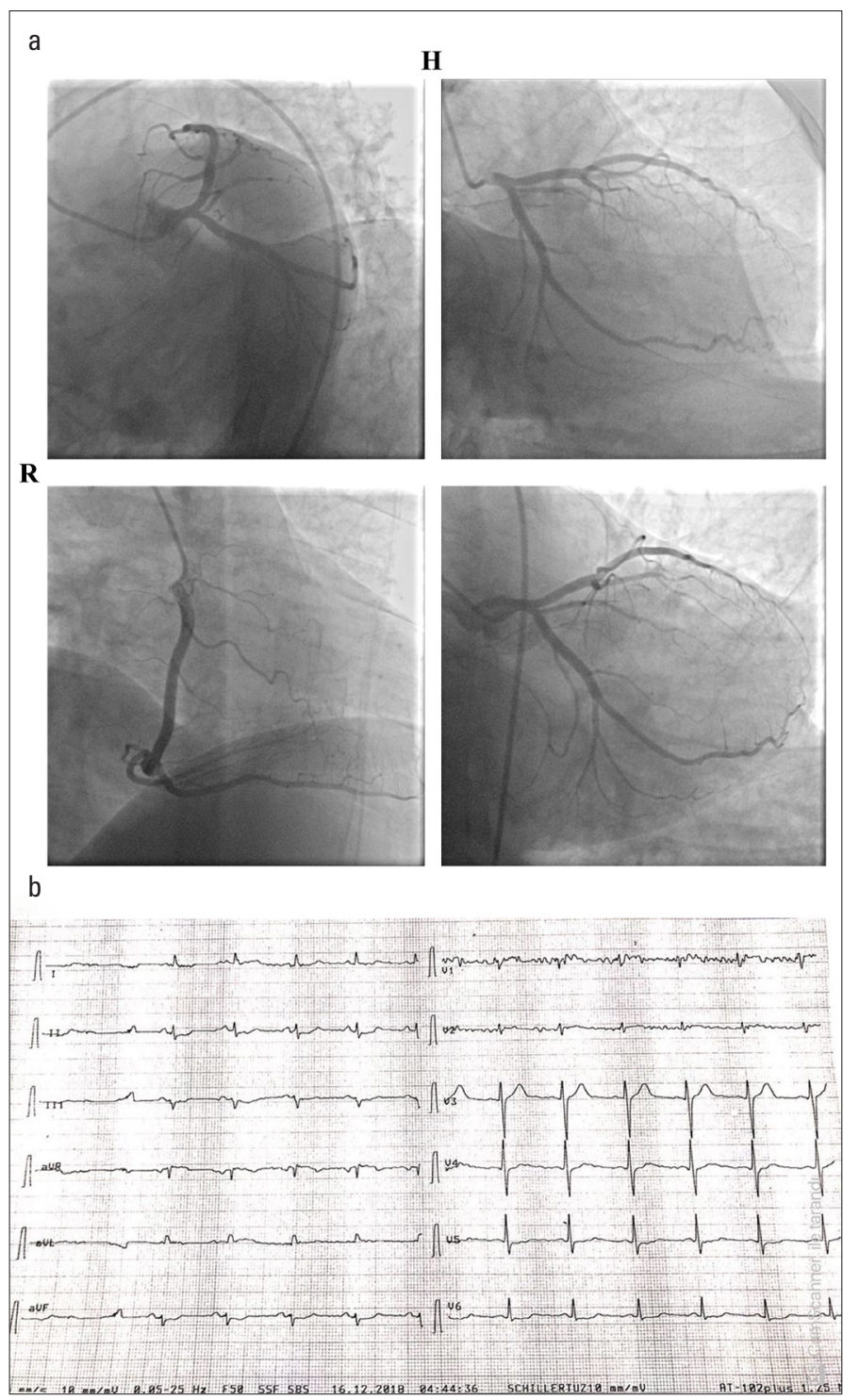

Figure 2. a) Coronary angiography of the patient. b) Control ECG of the patient

\section{Discussion}

The development of acute coronary syndrome after exposure to an allergen is not common. The association of allergic reactions and chest pain (accompanied by clinical and laborato- 
ry findings of angina pectoris) was first defined in 1991 and was named as "Kounis syndrome" (1, 3-5). Inflammatory mediators and various cytokines and chemokines contribute to KS (6). Mast cells secrete factors, such as histamine, tryptase, platelet activating factor, leukotrienes, and thromboxane, which have been shown to cause coronary artery spasm or plaque rupture in the coronary vessels (2). Moreover, KS is not a single-organ disease. It is allergy-hypersensitivity-anaphylaxis of various organs, including skin and respiratory and vascular systems, that can be affected by different treatment methods in various areas (2).

There are 3 variants of KS (7). Type 1 defines vasospasm and ischemia with normal coronary arteries without any risk factors or history of coronary artery disease, whereas type 2 develops on the basis of coronary artery disease and defines acute coronary syndrome caused by rupture of an atheroma plaque. Type 3 defines acute coronary syndrome that occurs with drug-eluting stent thrombosis, and the thrombus material removed reveals products secreted by mast cells (8).

Although penicillin is the most common antibiotic group to cause KS, there are rare reports of KS caused by ceftriaxone (9) or metronidazole (10).

In our patient, mast cell-based myocardial damage occurred shortly after the possible causative factors entered the body, and an acute coronary syndrome with ST elevation occurred. It is not clear, however, whether the main factor causing the KS was ceftriaxone or metronidazole or both. Our patient mimicked the type $1 \mathrm{KS}$ on the basis of coronary spasm.

\section{Conclusion}

The fact that such a clinical picture could be fatal should be considered. Acute coronary syndrome treatments (medical or invasive) in accordance with current guidelines should be offered to patients immediately, and care should be taken in the follow-up of patients. Furthermore, extensive research is required to elucidate the optimal treatment.
Informed consent: Informed consent was obtained from the patient.

\section{References}

1. Kounis NG, Zavras GM. Histamine-induced coronary artery spasm: the concept of allergic angina. Br J Clin Pract 1991; 45: 121-8.

2. Kounis NG, Koniari I, Velissaris D, Tzanis G, Hahalis G. Kounis Syndrome-not a Single-organ Arterial Disorder but a Multisystem and Multidisciplinary Disease. Balkan Med J 2019; 36: 212-21. [Crossref]

3. Biteker M. Current understanding of Kounis syndrome. Expert Rev Clin Immunol 2010; 6: 777-88. [Crossref]

4. Kounis NG. Kounis syndrome (allergic angina and allergic myocardial infarction): a natural paradigm? Int J Cardiol 2006; 110: 7-14. [Crossref]

5. Matucci, Rossi 0, Cecchi L, Vultaggio A, Parronchi P, Brugnolo F, et al. Coronary vasospasm during an acute allergic reaction. Allergy 2002; 57: 867-8. [Crossref]

6. Hasegawa S, Tashiro N, Matsubara T, Furukawa S, Ra C. A comparison of FcepsilonRI-mediated RANTES release from human platelets between allergic patients and healthy individuals. Int Arch Allergy Immunol 2001; 125 Suppl 1: 42-7. [Crossref]

7. Kounis NG. Kounis syndrome: an update on epidemiology, pathogenesis, diagnosis and therapeutic management. Clin Chem Lab Med 2016; 54: 1545-59. [Crossref]

8. Biteker M. A new classification of Kounis syndrome. Int $\mathrm{J}$ Cardiol 2010; 145: 553. [Crossref]

9. Saleh AA. Kounis syndrome: acute inferior myocardial infarction with atroventricular node block due to ceftriaxone: a first reported case. Ann Saudi Med 2014; 34: 250-3. [Crossref]

10. Terlemez S, Eryılmaz U, Tokgöz Y, Uysal P, Coşan A, Bulut Y. Kounis syndrome caused by metronidazole--a case of 14 year-old boy. Int J Cardiol 2015; 179: 222-4.[Crossref]

Address for Correspondence: Dr. Abdulkadir Çakmak, Amasya Üniversitesi Tıp Fakültesi, Kardiyoloji Anabilim Dalı, Amasya-Türkiye Phone: +90 3582122714

E-mail: cakmaka6@gmail.com

(C) Copyright 2021 by Turkish Society of Cardiology -

Available online at www.anatoljcardiol.com

DOI:10.5152/AnatolJCardiol.2020.36422 